\title{
The British Nutrition Foundation Oral Task Force Report — issues relevant to dental health professionals
}

\author{
P. Moynihan, 1
}

\section{A recent report on diet and oral health by the British Nutrition Foundation reviews the anatomy, microbiology and pathology of a number of oral diseases including dental caries, tooth-wear, oral cancer, periodontal disease and enamel defects. The role of nutritional factors in the aetiology and prevention of these oral diseases is discussed. The report states that improvements in the levels of caries in the UK are halting and remain unacceptably high in some 'at risk groups' - including the socially deprived. It states that a two-pronged attack, ie reduced frequency of consumption of sugary foods and use of fluoride is necessary to address the problem. To address the increased prevalence of oral cancer avoiding tobacco, limiting alcohol and increasing fruit and vegetable consumption are recommended. Recommendations for approaches to improve oral health are made for health authorities, industry, schools and health professionals and it is recommended that the Government make adequate resources available to improve oral health preventive strategies.}

n 1997 The British Nutrition Foundation
set up an Oral Health Task Force to review
and deliberate on issues relating to the rela-
tionship between diet and oral health. The
Task Force Report has recently been pub-
lished. ${ }^{1}$ The British Nutrition Foundation is
a major nutrition body with strong links
with industry, including many of the manu-
facturers of sugar-rich foods. The report is
likely to be widely read within the field of
nutrition, dietetics and dentistry. It is there-
fore important to review the document to
ensure that it presents a balanced and non-
biased account of the relationship between
diet and dental diseases. The aims of this
paper are therefore: to disseminate the main
conclusions and proposals for recommen-
dations made by the oral health task force

${ }^{1}$ Lecturer in Nutrition, Department of Child Dental Health, The Dental School, University of Newcastle Dental School, Framlington Place, Newcastle upon Tyne NE2 4BW

email:p.j.moynihan@ncl.ac.uk

REFEREED PAPER

Received 14.04.99; accepted 13.10.99

(c) British Dental Journal 2000; 188: 308-312 which are relevant to the clinical dentist; and to provide a critical appraisal of the report.

The report summarises data from the 1993 Child Dental Health Survey, ${ }^{2}$ the National Diet and Nutrition Survey (NDNS) of children aged 1.5 to 4.5 years $^{3}$ and the 1988 Adult Dental Health Survey, ${ }^{4}$ on disease patterns for dental caries and concludes

\section{In brief}

- The British Nutrition Foundation commissioned a task force to report on diet and oral health

- Improvements in dental caries' prevalence are halting - and both dietary control and fluoride use are required to address this

- Preventive measures against oral cancer include consuming high amounts of fruits and vegetables

- Health professionals need to be clear and consistent in the dietary advice given to patients

- More resources should be made available for oral health promotion that, despite a substantial decline in prevalence and experience of dental caries in children and young adults during the past 25 years (attributed mainly to regular use of fluoride toothpaste), the prevalence of dental caries in the UK remains unacceptably high. It is also concluded that the reduction in caries has ceased in young children, the rate of decrease has slowed down in adolescents and caries levels are higher in areas of multiple deprivation, the north of England and in non-fluoridated regions.

Of the 146-page report, less than a dozen pages are devoted to diet and dental caries and only 3 pages to diet and erosion. A disproportionate amount of space is devoted to background of oral anatomy, microbiology, basic nutrition and the caries process. The report also pays undue attention to the aetiology of enamel defects and periodontal disease only to state that nutritional factors play an insignificant role in these conditions.

Is 'non-milk extrinsic sugars/ intrinsic sugars' a meaningful classification?

The classification of carbohydrates according to their physical location, ${ }^{5}$ ie intrinsic sugars, non-milk extrinsic (NME) sugars, is discussed, because this classification has generated considerable debate. ${ }^{6}$ The report explains how criticism stems from the fact that, chemically, intrinsic and extrinsic sugars are indistinguishable and there is no difference in their physiological effects. It also states that there are problems of making a clear distinction between intrinsic and extrinsic sugars in foods (eg fruit yoghurt). There is evidence of reluctance to directly use the terms 'intrinsic sugars' and 'NME sugars' in the conclusions and recommendations of the report. What the report fails to highlight is that 'NME sugars' and 'intrinsic sugars' are useful terms for the purpose of dental health education.

Current intake of sugar in the UK The report presents data from the National Food Survey (NFS) ${ }^{7}$ on food intake accord- 
ing to family income. This shows an increase in intake of sugar and preserves with decreasing household income. This relationship is not observed for confectionery and the reverse trend is observed for soft drink consumption. The average intake of NMES per person per day for England is quoted as $53 \mathrm{~g}$, which is within the current UK recommendation of $<60 \mathrm{~g} / \mathrm{d} .{ }^{8}$ However, the report is misleading, as the NFS figure is an underestimate of current sugar intake in the UK. This is because NFS data refer only to household food purchases and do not include foods bought outside the home. Other research has shown that up to a third of food is consumed outside the home. ${ }^{9}$

\section{Orange juice, sweetened milk and sugared yoghurt are not cariogenic?}

The report states that because of the protective factors in dairy products (calcium, phosphate, protein and lipids) up to $10 \%$ sucrose may be added to milk without a significant fall in $\mathrm{pH}$ being recorded (this is equivalent to 12 teaspoons per pint!), however, no references are provided in the report to support the statement. In fact this is not true, as it has been reported elsewhere that a $10 \%$ solution of sucrose in milk results in plaque $\mathrm{pH}$ values lower than 5.5 in a low caries risk group. ${ }^{10}$ The report also states that the $\mathrm{pH}$ of yoghurt is less than 4.0, and that very few oral bacteria have the ability to produce acid from sugars at this $\mathrm{pH}$. Furthermore it is stated that any acids produced by fermentation of its constituent sugars would be insignificant compared with the microbial acids already existing in the product. Likewise the report states that the sugars present in fruit juices, especially citrus juices are not themselves harmful to teeth because the natural low $\mathrm{pH}$ of fruit juices has a deleterious effect upon dental plaque bacteria that usually metabolise sugar. These are also unwarranted assumptions (and are not backed up with references) because the $\mathrm{pH}$ of a foodstuff is not the same as the $\mathrm{pH}$ of the plaque following its consumption. Many factors influence the $\mathrm{pH}$ of the plaque including intrinsic buffering capacity and saliva flow and composition. In addition to this, cariogenic bacteria

Table 1 Summary of the proposals for recommendations for individuals made by the BNF Oral Health Task Force

\section{Recommendations}

- Brush teeth twice a day with a fluoride toothpaste of proven efficacy

- Limit the consumption of sugary foods and drinks to mealtimes

- Avoid cariogenic snacks and sugared drinks between meals

- Do not add sugars to bottles of infant formula or follow on formula

- Do not give drinks containing sugars or other fermentable carbohydrates in bottles or feeders, especially at bedtime

- Do not allow babies with teeth to fall asleep when feeding

- Ensure that, as far as possible, when medicines are given that they are sugar-free

such as $S$. mutans and lactobacilli, function at low $\mathrm{pH}$ values. Under test-tube conditions, bacteria may be inhibited when incubated with a foodstuff of $\mathrm{pH} 4$, however, it is inappropriate to extrapolate this to conditions at the plaque/enamel interface without supporting evidence.

\section{Dental caries: diet and nutrition}

The report briefly reviews the evidence for a relationship between sugars' consumption and dental caries, and concludes that sugars are the most important dietary factor in the aetiology of dental caries and that main sugars responsible are those in the free form, and added sugars. It is also concluded that there is no epidemiological evidence to show that those sugars enclosed within the cellular structure of the food have an important role in the aetiology of caries.

On reviewing the issue of whether it is frequency of amount of sugars consumed which influences dental caries, the report concludes that both are important, however, as these two factors are highly associated efforts to control one will control the other. The dietary recommendations to the individual to minimise caries therefore focuses on controlling frequency. These recommendations are summarised in Table 1. In agreement with the report, it is more pragmatic to control frequency of sugars consumption as this is easier to quantify and not as vague as advising to reduce amount of sugars consumed. However, the recom- mendation to limit sugar-rich foods to mealtimes and to avoid them in between meals may be meaningless to patients (especially children) who do not follow a structured meal pattern. It would have been more pragmatic to provide guidance on a numerical limit to the number of sugar intakes consumed each day (ie not more than four intakes of NME sugars a day) as a 'grazing' pattern of consumption is increasingly common.

\section{Do all carbohydrates cause dental caries?}

In view of current dietary recommendations to increase the intake of starchy foods and fruit by the UK population, ${ }^{8,11}$ the cariogenic potential of these foods is an important issue that was considered by the task force. It was concluded that although animal and laboratory studies show starchy foods can reduce the $\mathrm{pH}$ of plaque, there is no epidemiological evidence that consumption of starch-rich foods, without added sugars, play a significant role in the aetiology of dental caries.

Likewise, with reference to fruits, the report concludes that although experimental studies suggest that fresh fruit has the potential to cause caries, ${ }^{12}$ epidemiological evidence shows that fresh whole fruit plays little part in the development of caries. However, it does state that sugars in fruit juices and some of the sugars in pulped fruit are NME sugars. 
The report is lacking in that it provides no review, opinion or recommendations regarding other dietary carbohydrates such as maltodextrins, glucose syrup, and nondigestible oligosaccharides, or recommendations regarding the use of non-sugars sweeteners.

\section{Can fluoride alone prevent caries?}

The Oral Health Task Force reviewed the evidence relating to the role of fluoride in the prevention of dental caries and concluded that the reduction in dental caries observed during the last quarter of this century can be largely attributed to the widespread use of fluoride toothpaste and that water fluoridation programmes are among the most effective caries' preventive measures. The report also states that concerns regarding the safety of fluoride have not been substantiated by evidence. However, in terms of caries' prevention, it was recognised that although optimum fluoride in the oral environment dramatically reduces the risk of dental caries it does not eliminate the influence of sugar entirely and the report states that a twopronged attack, ie fluoridation and a reduction in the frequency and amount of consumption of 'extrinsic sugars', is required to minimise caries.

\section{Toothwear (tooth-tissue loss)}

The report reviews the limited data available on the prevalence and aetiology of non-carious tooth loss (toothwear, including erosion, abrasion and attrition) and the only conclusions drawn are that national data on the prevalence of tooth-wear are limited and that acidic foods and drinks have the potential to erode tooth surfaces. No dietary recommendations for the prevention and management of tooth-wear are given. The limited coverage of the subject reflects the lack of information available on diet and toothwear. There is a perception that the prevalence of toothwear is increasing, and there is some information on the prevalence of tooth-wear from the NDNS and Child Dental Health surveys, ${ }^{2,3}$ however, there have as yet been no repeated epidemiological surveys.

It would appear that in the absence of evidence-based practice, the Oral Health Task Force refrained from making recommendations in terms of dietary practices and toothwear. In view of the current unacceptably high levels of toothwear, and the perception that the prevalence is increasing, to offer no guidelines on dietary practices which may minimise the condition seems to be a shortfall of the report (for a common-sense approach to the dietary management of dental erosion see Rugg-Gunn and Nunn) ${ }^{13}$.

\section{Oral cancer}

The report concludes that in the UK, the prevalence of oral cancer is increasing and

\begin{tabular}{|c|c|c|c|c|c|}
\hline $\begin{array}{l}\text { Summ } \\
\text { Gover }\end{array}$ & $\begin{array}{l}\text { of the proposals } \\
\text { ent, Local Authorit }\end{array}$ & $\begin{array}{l}\text { ecommendations } \\
\text { industry, schools a }\end{array}$ & $\begin{array}{l}\text { BNF Oral Health Tas } \\
\text { ealth professionals }\end{array}$ & Force: & \\
\hline Health authorities & Local government & Central government & Industry & Health professionals & Schools \\
\hline $\begin{array}{l}\text { Persuade water } \\
\text { companies to } \\
\text { fluoridate } \\
\text { water supplies }\end{array}$ & $\begin{array}{l}\text { Support the Health } \\
\text { Authority in the } \\
\text { promotion of oral health }\end{array}$ & $\begin{array}{l}\text { Amend Fluoridation Act } \\
\text { to require water } \\
\text { companies to fluoridate } \\
\text { supplies if health } \\
\text { authorities } \\
\text { recommend so }\end{array}$ & $\begin{array}{l}\text { Water companies: } \\
\text { fluoride supplies when } \\
\text { asked to do so by health } \\
\text { authorities }\end{array}$ & $\begin{array}{l}\text { Increase efforts to } \\
\text { educate patients with } \\
\text { consistent and effective } \\
\text { advice on oral health } \\
\text { (in line with advice in } \\
\text { Table 1) }\end{array}$ & $\begin{array}{l}\text { Educate children about } \\
\text { the importance of tooth- } \\
\text { brushing in relation to } \\
\text { oral health }\end{array}$ \\
\hline $\begin{array}{l}\text { Collect more data on } \\
\text { groups at high risk of } \\
\text { oral diseases }\end{array}$ & $\begin{array}{l}\text { Enforce existing } \\
\text { legislation on } \\
\text { advertising, sale and } \\
\text { consumption of alcohol } \\
\text { and tobacco more } \\
\text { effectively }\end{array}$ & $\begin{array}{l}\text { Give appropriate } \\
\text { priority to, and make } \\
\text { resources available for, } \\
\text { oral health promotion }\end{array}$ & $\begin{array}{l}\text { Food companies and } \\
\text { retailers: increase } \\
\text { choice and availability } \\
\text { of affordable non-cariogenic } \\
\text { snack foods and drinks }\end{array}$ & $\begin{array}{l}\text { Take opportunities for } \\
\text { appropriate in service } \\
\text { training on oral health } \\
\text { promotion }\end{array}$ & $\begin{array}{l}\text { Educate children about } \\
\text { the importance of diet in } \\
\text { relation to oral health as } \\
\text { well as health in general }\end{array}$ \\
\hline \multicolumn{2}{|l|}{$\begin{array}{l}\text { Target oral health } \\
\text { promotion to at risk } \\
\text { groups }\end{array}$} & $\begin{array}{l}\text { Collect more data on } \\
\text { groups at risk of oral } \\
\text { diseases }\end{array}$ & $\begin{array}{l}\text { Adopt full nutrition } \\
\text { labelling to include } \\
\text { information on sugars }\end{array}$ & $\begin{array}{l}\text { Use effective } \\
\text { preventive technologies } \\
\text { and oral health } \\
\text { counselling for patients } \\
\text { at risk of oral diseases }\end{array}$ & $\begin{array}{l}\text { Provide and encourage } \\
\text { the use of non-cariogenic } \\
\text { snacks and drinks } \\
\text { between meals }\end{array}$ \\
\hline \multirow{3}{*}{$\begin{array}{l}\text { Provide ongoing } \\
\text { training for all health } \\
\text { professionals to ensure } \\
\text { consistent messages in } \\
\text { the promotion of oral } \\
\text { health }\end{array}$} & & $\begin{array}{l}\text { In the absence of water } \\
\text { fluoridation, consider } \\
\text { other vehicles for } \\
\text { fluoride }\end{array}$ & $\begin{array}{l}\text { Pharmaceutical } \\
\text { companies: continue to } \\
\text { develop and make } \\
\text { sugar-free medicines }\end{array}$ & & \\
\hline & & $\begin{array}{l}\text { Include oral health } \\
\text { benefits in health } \\
\text { education campaigns } \\
\text { against tobacco and } \\
\text { alcohol }\end{array}$ & $\begin{array}{l}\text { Oral healthcare product } \\
\text { companies: continue to } \\
\text { improve the } \\
\text { effectiveness of oral } \\
\text { healthcare products }\end{array}$ & & \\
\hline & & $\begin{array}{l}\text { Consider strengthening } \\
\text { present legislation on } \\
\text { issues concerning } \\
\text { tobacco advertising, } \\
\text { sale and use }\end{array}$ & & & \\
\hline
\end{tabular}


the age of presentation is decreasing. The role of diet, and other factors, in the aetiology is reviewed and the report concludes that tobacco smoking and high alcohol consumption are the two most important risk factors. Evidence from meta-analyses is also presented which shows that dietary fibre and vitamin $C$ intakes are inversely related to oral cancer. ${ }^{14}$ The report also concludes that there is epidemiological evidence to indicate that high fruit and vegetable consumption may offer a protective effect. The task force recommends that to avoid oral cancer, the use of tobacco is avoided, that alcohol should be limited to approximately three units a day and that a balanced diet including a high intake of fruits and vegetables (five portions a day) is consumed.

\section{Oral health of infants and children}

The chapter of the report that addresses dental health in children states that the decline in dental caries in children is decreasing and in younger children has ceased, and that in pre-school children consumption of sugars is double the recommended maximum. The report highlights several dietary practices such as snacking, skipping meals and 'dieting' which are increasingly common in children and which increase the risk of dental diseases. It states that if these practices are to be accepted, then snacks that are least harmful to teeth should be encouraged. Fresh fruit, cheese, peanuts and chewing gum (especially the sugar-free varieties) are given as examples but caution was expressed with regard to some varieties of crisps and corn snacks that may contain up to $22 \%$ sugars.

The dietary practices associated with caries in infants and pre-school children are reviewed. Concern was expressed over toothwear in this age group and the low $\mathrm{pH}$ of baby juice drinks. The report states that the low $\mathrm{pH}$ (around 3.5) and high titratable acidity of baby juices, if in contact with teeth for a long time, will cause enamel loss and that diluting juices to one tenth will only increases the $\mathrm{pH}$ to $4.0-$ a level at which enamel loss may still occur. The recommendations of the Task Force for infant feeding are presented in Table 1.

\section{Dental status of older people}

The report reviews the dental and oral health status of the elderly and presents some interesting data from the recently published NDNS Survey of people aged 65 years and over, ${ }^{15}$ which indicated that $50 \%$ of persons more than 65 years of age are edentulous and an additional $26 \%$ of dentate subjects have no teeth in one arch. Summarising data from the NDNS study and other published research, ${ }^{15,16}$ the report states that those with fewer opposing pairs of teeth and the edentulous have low intakes of non-starch polysaccharide (dietary fibre), vitamin C, (both associated with a higher risk of oral cancer) and other nutrients, and lower serum concentrations of vitamin C, vitamin A and vitamin E. The report concludes that these nutritional consequences of tooth loss are likely to have an effect on the overall health and welfare of the individual. However, the report makes no recommendations on how to reduce the risk of nutrition-related problems in those with impaired masticatory function.

The report highlights the high prevalence of root caries in the elderly (between 60 to $90 \%$ ) and concludes that reduced salivary flow and frequency of sugar intake are risk factors associated with the disease. The report states that alleviation of dry mouth by sucking of sweets should be discouraged because of the cariogencity and sometimes acidic nature of sweets.

\section{People from areas of multiple deprivation}

The report highlights the findings of several national surveys stating that those from areas of multiple deprivation are at increased risk of poor oral health because of poorer oral hygiene, diet and dental attendance. Deprived communities consume more cariogenic food and practice eating patterns associated with dental caries. Poverty restricts freedom and choice and the ability to comply with formal dental health education. The report recommends that further research into effective oral health promotion strategies in this group is needed and that more resources should be made available to improve access and treatment in deprived communities (Table 2).

\section{Recommendations}

The Oral Health Task Force proposed a number of recommendations from the level of the individual to central Government (Tables 1 and 2). Several of these recommendations are in line with the Government aim to reduce health inequalities, outlined in the White Paper Our Healthier Nation. However, the report highlights the fact that oral health is an important component of health inequality that should not be overlooked.

The recommendation for health authorities to provide ongoing training of all health professionals to ensure consistency of messages is welcomed as many dentists will not have the benefit of the increase nutrition content of the undergraduate curriculum of today, and nutrition undergraduate training is sadly lacking in oral health issues.

The recommendation to manufacturers to increase the production of affordable sugar-free or low sugar snacks and for schools to provide them seems a pragmatic approach to dealing with the snacking culture of today. It is recommended that the Government make available adequate resources for oral health promotion which is essential if the recommendation for dentists to practice effective preventive oral health measures is to be achieved.

\section{Conclusions}

The British Nutrition Foundation's Oral Health Task Force Report presents a broad overview of oral health and nutritional factors which may be useful to the clinical dentist as it brings together information form a number of recent reports including the NDNS surveys, COMA reports and the dental health surveys of children and adults. In general a non-biased, balanced account of diet and oral health is provided along with some useful proposals for recommendations However, no strategy for dissemination and implementation of the Task Force recommendations are given and therefore the impact of this report remains to be seen. 
1 Arens U. Oral Health Diet and Other Factors. Amsterdam: The Report of the British Nutrition Foundation's Task Force, 1999.

2 O'Brien M. Children's Dental Health in the United Kingdom 1993. London: Office of Population Censuses and Surveys, 1994.

3 Hinds K, Gregory J R. National Diet and Nutrition Survey: children aged 1.5 to 4.5 years, vol 2: Report of the Dental Survey. London: HMSO, 1995.

4 Todd J E, Lader D. Adult Dental Health 1988; United Kingdom. London: HMSO, 1991.

5 Department of Health. Dietary Sugars and Human Disease. Report on Health and Social Subjects No 37. London: HMSO, 1989.

6 Johnson I T, Southgate D A T, Durnin J V G A. Intrinsic and non-milk extrinsic sugars: does the distinction have analytical or physiological validity? Int J Food Sci Nutr 1996; 47: 131-140.

7 MAFF. National Food Survey 1996. London: HMSO, 1997.

8 Department of Health. Dietary Reference Values for Food Energy and Nutrients in the UK. Report on Health and Social Subjects No 41. London: HMSO, 1991.

9 Adamson A J. Nutrient intakes (1990 compared with 1980) and place of purchase of foods (1990) by 11- to 12-year-old Northumbrian children. Newcastle upon Tyne, 1993.

10 Moynihan P J, Gould M E L, Huntley N, Thorman S. Effect of glucose polymers in water, milk, and a milk substitute on plaque $\mathrm{pH}$ in vitro. Int J Paediatr Dent 1996; 6: 19-24.

11 Department of Health. Nutritional Aspects of Cardiovascular Disease. Report on Health and Social Subjects No 46. London: HMSO, 1994.
12 Edgar W M, Bibby B G, Mundorff S, Rowley J. Acid production in plaques after eating snacks: modifying factors in foods. J Am Dent Assoc 1975; 90: 418-425.

13 Rugg-Gunn A J, Nunn J H. Nutrition, Diet and Oral Health. Oxford: Oxford University Press, 1999.

14 Macfarlane G J. The epidemiology of oral cancer. University of Bristol, 1993.

15 Steele J G, Sheiham A, Marcenes W, Walls A G. National Diet and Nutrition Survey: people aged 65 years and over. Vol 2: Report of the Dental Survey. London: HMSO, 1998.

16 Moynihan P J, Snow S, Jepson N J A, Butler T J. Intake of non-starch polysaccharide (dietary fibre) in edentulous and dentate persons: an observational study. Br Dent J 1994; 177: 243-247.

\section{BDA Information Centre Services}

\section{Did you know?}

- As a BDA member you can gain access to one of the best dental information services in the world

- You don't have to be based in London to use the service

- You can borrow books, videos and information packages

- You can borrow up to eight items via the postal system

The only cost to you is the cost of the return postage. If you're not sure what to request then telephone us and we can advise you.

- You are entitled to free MEdLINE searches

Telephone us with a subject and we will send you a list of relevant references with abstracts.

\section{- You can request photocopies of journal articles}

There is a small charge for this service and you need to fill in a Photocopy Request Form first. Telephone us if you would like one of these forms.

- You can register to receive free Current Dental Titles

These are MEDLINE-based lists of references on eight areas of dentistry which are sent to you automatically twice a year. Phone us for a registration form.

For further details of any of these services dial $01719350875 \times 265$. or contact us via e-mail at: Infocentre@bda-dentistry.org.uk Visit the Information Centre web pages at: www.bda-dentistry.org.uk 